Instructions for authors, subscriptions and further details:

http://brac.hipatiapress.com

\title{
El Problema de la Verdad en los Fakes Mediáticos Activistas
}

Elena Gabriela Fraj Herranz ${ }^{1}$

1) Facultad de Bellas Artes, Universidad de Barcelona. España.

Date of publication: June $3^{\text {rd }}, 2018$

Edition period: February 2018 - June 2018

To cite this article: Fraj Herranz, E. G. (2018). El Problema de la Verdad en los Fakes Mediáticos Activistas. Barcelona, Research, Art, Creation, 6(2), 135-152. doi: 10.17583/brac.2018.2495

To link this article: http://dx.doi.org/10.17583/brac.2018.2495

\section{PLEASE SCROLL DOWN FOR ARTICLE}

The terms and conditions of use are related to the Open Journal System and to Creative Commons Attribution License (CC-BY). 


\section{The Problem of Truth in Activist Mediatic Fakes}

Elena Gabriela Fraj Herranz.

Faculty of Fine Arts, University of Barcelona. Spain.

(Received: 9 January 2017; Accepted: 2 April 2018; Published: 3 June 2018)

\section{Abstract}

Activist fakes are actions that hack dominant mass media. In order to create hoaxes, tactics as simulation of visual codes, identity theft, rhetorical and ironic language are used. The result is a paradox because by deceiving truth is revealed. However, what's the meaning of truth in this context? With the aim of figure out this issue we consider two cases study, The Yes Men (2009) and Ikastrolla (2013). They are symptomatic of such interventions because they present the main features in common. Whit the goal of do an analysis, a research methodology is designed on the basis of culture analyse and grounded theory tools. We choose concepts coming from other areas to sketch a theory whenever the research moves forward. Truth and power and the relationship between them are the chosen concepts as of Michel Foucault contributions. As key findings of the analysis we have found that deceptions do not have a dialectical relationship between truth and falsity where truth is objectified pre-existing and its representation. Instead they provide visual and discursive complexity with which expose the mechanisms that articulate the truth written in the dominant discourses of power.

Keywords: fake, activism, hackers, mass media. 


\section{El Problema de la Verdad en los Fakes Mediáticos Activistas}

Elena Gabriela Fraj Herranz.

Facultad de Bellas Artes, Universidad de Barcelona. España.

(Recibido: 9 enero 2017; Aceptado: 2 abril 2018; Publicado: 3 junio 2018)

\section{Resumen}

Los fakes activistas son acciones que hackean los medios de comunicación dominantes. Para construir el engaño utilizan tácticas de simulación de códigos visuales, de suplantación de identidades y emplean la ironía. Se produce una paradoja ya que mediante el engaño se desvela una verdad. Pero ¿qué significa el concepto de "verdad" en este contexto? Para desentrañar el conflicto se estudian dos casos, The Yes Men (2009) e Ikastrolla (2013), los cuales son sintomáticos porque presentan características comunes en este tipo de intervenciones. Para realizar el análisis se diseña una metodología de investigación basada en las herramientas del análisis cultural y de la teoría fundada. Se escogen conceptos de otras disciplinas con los que esbozar una teoría a medida que avanza el análisis. Los conceptos elegidos son verdad y poder y la relación que se da entre ambos a partir de las aportaciones del filósofo Michel Foucault. Como conclusiones del análisis se desprende que los engaños no presentan una relación dialéctica entre verdad y falsedad donde la verdad es preexistente y objetivable a su representación, sino que aportan complejidad visual y discursiva gracias a la cual dejan al descubierto los mecanismos que articulan la verdad inscrita en los discursos dominantes del poder.

Palabras clave: falsificación, activismo, hackers, medios de comunicación. 


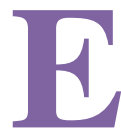

1 activismo es aquel conjunto de acciones que pretenden intervenir sobre cuestiones que afectan a la sociedad con el objetivo final de transformarla. A partir de esta definición construida expresamente en este estudio se profundiza en los métodos utilizados para conseguir los cambios propuestos. Así, las acciones de protesta necesitan visibilizar y atraer la atención sobre los asuntos cuestionados y, es por ello, por lo que se hace fundamental el uso de los medios de comunicación. Existe una larga trayectoria histórica en la que puede constatarse cómo los antagonismos políticos se han preocupado por construir sus propios medios, unos medios alternativos a los oficiales, así como también esos antagonismos han tratado de acceder a los medios de comunicación dominantes, con más o menos éxito. Sin embargo, esta segunda vía no está desprovista de problemas, pues la representación de los conflictos por parte de los medios nunca es neutra. El sociólogo y filósofo Maurizio Lazzarato (2006) explica que los sujetos hablantes que aparecen en la televisión acaban, paradójicamente, siendo enunciados a sí mismos. Se encuentran, sin quererlo, siendo causa y origen del enunciado ya que son dominados por una máquina que interpreta, selecciona, normaliza y que acaba por agenciarse de los cuerpos con el objetivo de incluirlos en su propio flujo. De este modo, a los antagonismos políticos no les basta con atraer el foco de los medios, sino que también han de entender cómo funcionan sus mecanismos de enunciación. Han de pensar de qué manera, cómo y en qué momento es posible hablar en los canales mediáticos que participan de la esfera pública dominante sin que sean fagocitados por los mismos. Éste es el conflicto inherente a los medios de comunicación, que obliga a que las voces críticas activistas tengan que operar en ocasiones con los mecanismos de una guerrilla. Y, en tanto que guerrilla, han de planificar una resistencia organizada mediante la táctica, una resistencia que echa mano de la creatividad y del ingenio para poder abrir grietas en la maquinaria mediática y recuperar así la capacidad del habla.

En las últimas décadas buena parte de las prácticas activistas han utilizado unos procedimientos comunes para intervenir en los medios. Entre todos ellos son destacables las operaciones de construcción de falsificaciones. Los llamados fakes mediáticos son procedimientos que se basan en el hackeo 
efectuado sobre el lenguaje de los media. Este tipo de hackeo es el resultado del uso de unas tácticas concretas, a saber: la simulación, la suplantación y la ironía. Estos mecanismos de actuación permiten acceder a esos medios al mismo tiempo que son capaces de generar una alteración de los códigos de enunciación establecidos y cuestionar tanto los canales y los significantes como los significados de las visualidades dominantes.

\section{Planteamiento del Problema}

En este artículo se tratará de identificar el problema de la verdad, el cual emerge a partir de la relación que se da entre realidad y representación inherente a este tipo de procesos. Para construir el engaño los fakes utilizan herramientas como la simulación, la suplantación y la retórica con el objetivo de desvelar una información. Se da la situación paradójica de que mediante el engaño se desvela una verdad, pero ¿a qué nos referimos con "verdad"?

La hipótesis que se plantea es que la verdad no puede ser entendida desde una focalización ideológica moderna donde se da una relación dialéctica. Se plantea que los fakes mediáticos son acciones que no pertenecen al contexto del arte militante o político en sentido moderno sino al contexto del arte activista en la época postmoderna. Por tanto, no podemos aceptar que la verdad preexiste a su desvelamiento ya que no se puede acceder a ella mediante el uso de un método científico como se podría proponer desde una focalización marxista. La pregunta sobre qué tipo de verdad se desvela en los casos estudiados es lo que vamos a tratar de responder.

\section{Metodología}

Con la intención de responder la hipótesis planteada se utilizan varias herramientas metodológicas. Para realizar el análisis se seleccionan, primero, dos casos de estudio sintomáticos y, después, se utilizan las herramientas del análisis cultural proveniente de los estudios culturales y de la hermenéutica. Se parte de una serie de conceptos teóricos con los que poder apuntar una teoría mediante el proceso de análisis. 


\section{La Hermenéutica}

El tipo de metodología de investigación que se lleva a cabo se apoya en la hermenéutica desarrollada por Gadamer (2007-2010). El análisis de los casos de estudio se realizará atendiendo a su carácter lingüístico y al diálogo entre el horizonte histórico, el sujeto investigador y los propios objetos. La hermenéutica permitirá construir una metodología específica para este estudio. Como parte importante se incluye parte de la metodología cualitativa de la teoría fundada. Esta metodología consiste en ir construyendo la teoría a la vez que se recopilan los datos y se avanza en la investigación. El proceso es diferente al de las metodologías cuantitativas, las cuales parten de una teoría que sostiene el estudio, o bien suelen concluir con propuestas teóricas solamente al final de la investigación, después de llevar a cabo un proceso deductivo. En el caso de la metodología de la teoría fundada, la teoría se va construyendo mientras se investiga, lo cual requiere que la arquitectura que sostiene la investigación no sea rígida.

"La teoría fundada es una metodología general para desarrollar teoría a partir de datos que son sistemáticamente capturados y analizados; es una forma de pensar acerca de los datos y de poderlos conceptualizar. La teoría se va desarrollando durante la investigación en curso mediante el continuo interjuego entre los procesos de análisis y recolección de datos. Su principal fundamento conceptual es el interaccionismo simbólico, pero se alimenta también de los desarrollos de algunos otros teóricos de la sociología cualitativa, entre ellos, Erving Goldman y George Simmel" (Sandoval 1996, p. 71).

\section{El Análisis Cultural}

La construcción de la metodología específica se articula sobre las herramientas que proporciona el análisis cultural. El análisis cultural procede del área de los estudios culturales, un campo de investigación de carácter interdisciplinar que se dedica a explorar las formas de producción y de creación de significados. Desde la perspectiva de los estudios culturales, la cultura no se concibe como una práctica, ni como la descripción de la suma de hábitos y costumbres de una sociedad. La cultura atraviesa todas las 
prácticas sociales y es el resultado de la suma de las interacciones que se dan entre estas prácticas. El interés de los estudios culturales se centra en definir el estudio de la cultura propia de la sociedad contemporánea como un terreno de análisis conceptualmente importante, pertinente y teóricamente fundado. En el concepto de cultura caben, tanto los significados y los valores que surgen y se difunden entre las clases y grupos sociales, como las prácticas efectivamente realizadas, a través de las que se expresan valores y significados. En términos generales podemos afirmar que los estudios culturales entienden los objetos de estudio como prácticas culturales según sus relaciones con el poder (Sardar, Van Loon, \& Appignanesi 2005). Tienen el objetivo de comprender la cultura en toda su complejidad, analizan el contexto político y social y son capaces de ser tanto objeto de estudio como lugar de la crítica y de la acción política. La investigadora y artista Mieke Bal (2002) revisa el campo de los estudios culturales y propone cambiar algunas de las premisas asumidas. Como los estudios culturales, el análisis cultural es interdisciplinar ya que utiliza diferentes metodologías procedentes de diferentes disciplinas. Pero la principal diferencia radica en que los estudios culturales se apoyan en teorías mientras que el análisis cultural se apoya en conceptos. Es en este punto en el que el análisis cultural se convierte en un método utilizable en el marco de la teoría fundada, pues no se trata de partir de teorías ni de llegar a ellas al final de la investigación sino de poder ir apuntándolas durante el proceso.

\section{Selección y Justificación de los Casos de Estudio}

Los casos de estudio escogidos son considerados sintomáticos respecto del contexto del que proceden, de los procedimientos que utilizan y de los efectos comunes que generan. The Yes Men (Estados Unidos, 1999-) es un colectivo formado por los jammers Mike Bonanno y Andy Bichlbaum (Estados Unidos-Francia). Se selecciona una acción que aparece relatada en la película The Yes Men Fix the World (Bichlbaum, Bonanno, \& Engfehr 2009). Esta acción consiste en la suplantación de la empresa Dow Chemical (2004), responsable última del accidente en la planta química de Bhopal, India. Los artistas suplantan a la empresa para anunciar en el canal de televisión de la BBC la asunción de la responsabilidad y la consecuente 
indemnización a las más de 500.000 personas víctimas del desastre (véase Imagen 1). Este colectivo se enmarca en el contexto de las luchas altermundistas que surgen a finales de los años noventa y continúan en la primera década de los dos mil. The Yes Men se dedica a suplantar identidades de multinacionales o de responsables políticos con el objetivo de engañar a los medios de comunicación y hablar en nombre de los sujetos suplantados. Son los mismos autores los que realizan las performances y se encarnan en las identidades falsas. Las noticias y los discursos que elaboran ponen en cuestión la legitimidad y el compromiso ético de las empresas o personajes públicos suplantados. El segundo caso es Ikastrolla (España, 2013). En el contexto post 15M en España un grupo de usuarios y usuarias de la red social Twitter compuesto por siete personas actúa de forma anónima para crear suplantaciones de cuentas en esta la red y emitir mensajes confusos. A este tipo de comportamientos que tienen por objetivo provocar confusión en las redes se le llama comúnmente troleo. Entre los objetivos de las suplantaciones con más impacto en la red se encuentran los fakes del personaje político Elena Valenciano (PSOE) y de la empresa El Corte Inglés, este último escogido para el análisis. Es un tipo de acción similar a las realizadas por el colectivo The Yes Men. La fuente consultada para analizar las acciones procede del vídeo The Troll Face, realizado por Ikastrolla (2013) y proyectado en el festival "The Influencers."
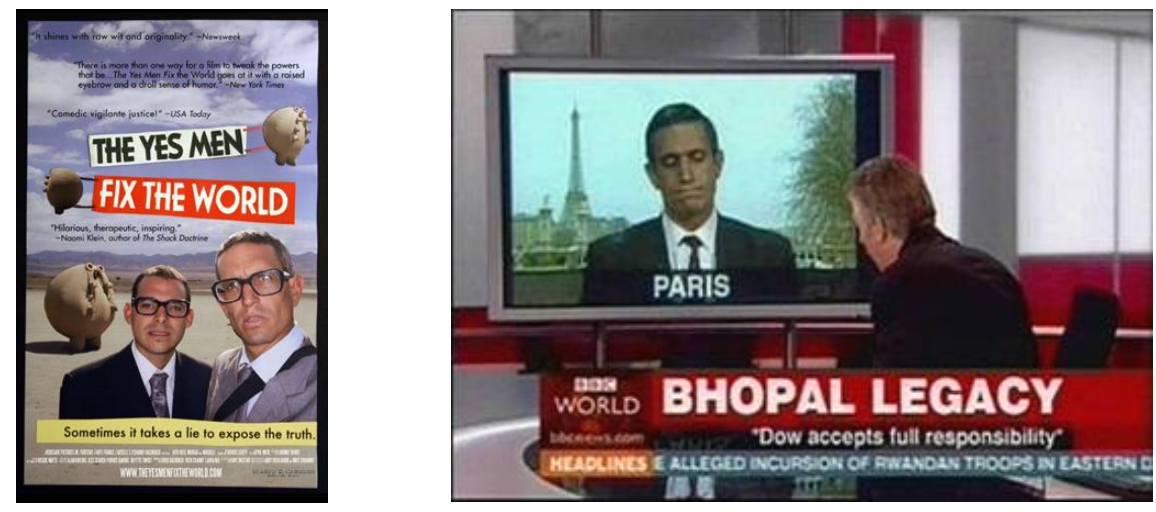

Imagen 1. Cartel y frame de la película The Yes Men Fix The World (2009). Recuperado de http://www.shadowdistribution.com/the-yes-men-fix-the-world/ 


\section{Análisis}

\section{El Hackeo Activista como Marco Teórico}

Tal y como apuntan Enmanuel Rodríguez y Raúl Sánchez (2004, p. 14) mientras la izquierda tradicional ignoraba esta nueva configuración, el desarrollo del software libre, las comunidades de hackers y mediactivistas herederas de la literatura ciberpunk de los años ochenta y de la contracultura estadounidense y europea, entre otros, aparecen como luchas a esta forma del capital. Las prácticas mediactivistas entienden la producción de imágenes culturales como el lugar para la transformación, tanto desde la propia organización y explotación que posibilite un reparto de la monetización de los saberes y conocimientos más justa y no monopolizada, como ejemplifica el desarrollo de software libre y otros muchos ejemplos de producción de cultura libre, como desde la significación simbólica de las propias imágenes. Los activistas mediáticos o también llamados culture jammers (Dery, 1984) en el contexto anglosajón hackean el marketing para producir otro tipo de sentido, se reapropian de las imágenes publicitarias ignorando los límites de la legalidad, utilizan juegos semánticos para operar sobre los significados. El culture jamming y, por ende, los fakes son una forma de hackeo no confrontativo que se apropia de los códigos. Para ello utilizan la retórica, la comedia y el engaño, éste último centro del estudio que sigue a continuación.

\section{Verdad y Dialéctica en el Arte Político}

Si el engaño es el asunto que estamos tratando es necesario, en consecuencia, abordar la cuestión de la verdad. El engaño significa la falta a la verdad, pero ¿a qué nos referimos con verdad? Los y las activistas que utilizan las tácticas del fake visibilizan un conflicto al mismo tiempo que desvelan un cierto tipo de verdad. Las tergiversaciones de los signos dominantes son operaciones que afirman un enunciado a la vez que lo niegan. Nos topamos con esa afirmación expresada mediante la negación, pero al final, también nos encontramos con una afirmación de una verdad. 
La frontera entre lo objetivo y lo subjetivo se rompe y es desde la subjetividad desde donde poder examinar "los intersticios que se intuyen en una realidad mediática empeñada en seguir simulando que actúa objetivamente; o bien ataca de manera directa este discurso con nuevas formas retóricas o con actuaciones personales de carácter panfletario." (Català 2013, p. 330). Para realizar el estudio se utilizan a continuación las herramientas metodológicas proporcionadas por el análisis cultural. A partir del concepto de verdad apuntado por Bertolt Brecht (1984) y sobre todo a partir del concepto de verdad en relación al poder que propone el filósofo M. Foucault (1981) se analiza la cuestión de la verdad en los fakes activistas.

Durante el periodo entre la Primera y la Segunda Guerra Mundial justo cuando el fascismo y el comunismo están en auge, el dramaturgo Bertolt Brecht (1984) escribe una serie de textos sobre la relación entre arte y política. El fascismo, sostiene, no es provocado por la barbarie, no se trata de una fuerza natural desprovista de cultura y civilización. Se deben analizar dialécticamente las relaciones entre economía e historia, pues el fascismo se da por una serie de razones, de causas, de mecanismos racionales y, además, no se puede condenar el fascismo sin condenar el capitalismo porque van de la mano. Interpela a los escritores de la época y les sugiere escribir sobre la verdad, en lugar de doblegarse ante los poderosos que les pagan el sueldo.

"Para los que escriben es importante encontrar el tono de la verdad. Por lo regular se oye por ahí un tono suave, quejumbroso, el de las gentes que no son capaces de matar una mosca. El que escucha este tono y está en la miseria, se hace más miserable. Así hablan algunos que quizá no son enemigos, pero indudablemente no son compañeros de lucha. La verdad es algo belicoso, no combate únicamente la falsedad, sino también a determinadas personas que la difunden." (Brecht 1984, p. 164)

El argumento de Brecht está apoyado sobre la relación dialéctica entre verdad y falsedad. El paradigma del momento político de la época del dramaturgo se basa en el antagonismo representado entre dos polos, el fascismo y el comunismo. Los fakes que realizan The Yes Men e Ikastrolla apelan también al binomio verdad-falsedad pero ¿se trata también de una relación dialéctica? Tomemos el caso de la acción donde The Yes Men suplanta a la empresa Dow Chemical (2004). Los artistas suplantan a un 
portavoz de la compañía para anunciar en el canal de televisión de la BBC que indemnizará económicamente a las víctimas de la tragedia de la planta química de Bhopal. El resultado obtenido es que las empresas no tienen otra opción que desmentir públicamente el anuncio y reafirmar su elusión de responsabilidad del caso. Los autores construyen una mentira de forma que la organización a la que se refieren tiene que afirmar que, esa mentira, es mentira. De este modo, mediante la negación de una falsedad, aparece una afirmación. El fake muestra que los beneficios económicos de la empresa están por encima de cuestiones éticas. No descubren datos ocultos, pero fuerzan a la empresa a mostrar un determinado rostro.

En el caso de las cuentas falsas en Twitter creadas por Ikastrolla sucede algo similar. La acción en la que suplantan a la empresa El Corte Inglés (2013) consiste en emitir mensajes públicos desde un perfil falso. Los productos textiles de El Corte Inglés, así como de otras empresas españolas eran facturados en una planta textil en Bangladesh que se hundió y en la que murieron 1.127 personas y 2.800 resultaron heridas. La cuenta falsa consiguió que la prensa recogiera el suceso de la suplantación poniendo así en el centro de la agenda mediática la responsabilidad no asumida de la empresa española. El proceso de sobreidentificación es el mismo proceso que utilizan los miembros de The Yes Men. En en el caso de Ikastrolla los mensajes que se difunden no son para anunciar que la empresa asume la responsabilidad sino para todo lo contrario, se reafirman en que no se hacen responsables del accidente ni de las condiciones laborales de los trabajadores y trabajadoras (véase Imagen 2). Los mensajes son exagerados y extremadamente cínicos (véase Imagen 3).

Si el principio de sobreidentificación como táctica activista en la acción de suplantación de Dow Chemical consiste en hacer decir a las empresas que su comportamiento no es ético, este principio funciona en Ikastrolla mediante la híper-representación del cinismo. Por tanto, si bien es cierto que los fakes se apoyan en la falsedad y en la verdad, la relación entre estos dos conceptos es más compleja de lo que a priori parece. 

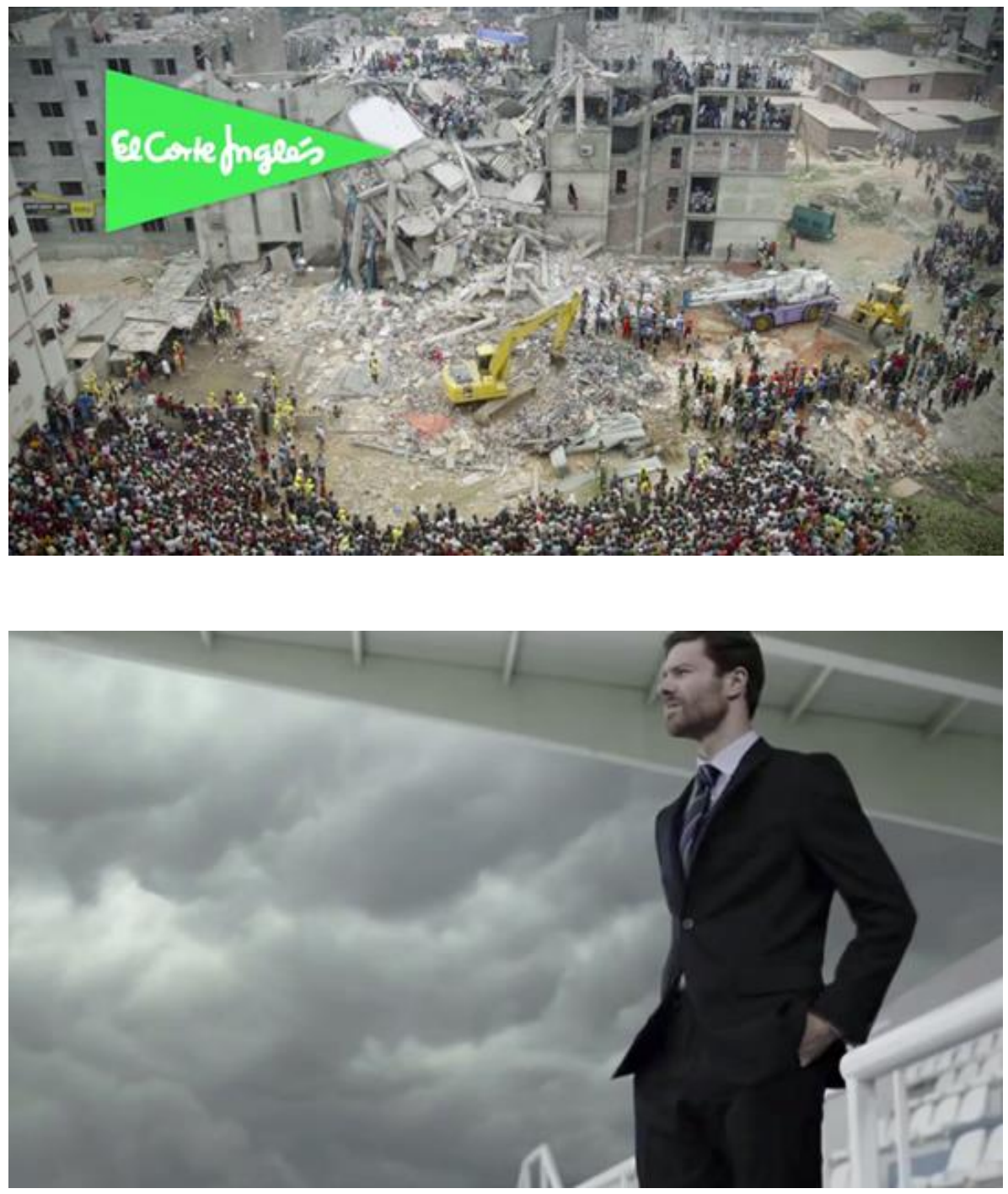

Imagen 2. Ikastrolla. Frames del video The Troll Face. Plano-contraplano. (2013). Acción de suplantación de El Corte Inglés. Recuperado https://vimeo.com/88515951 


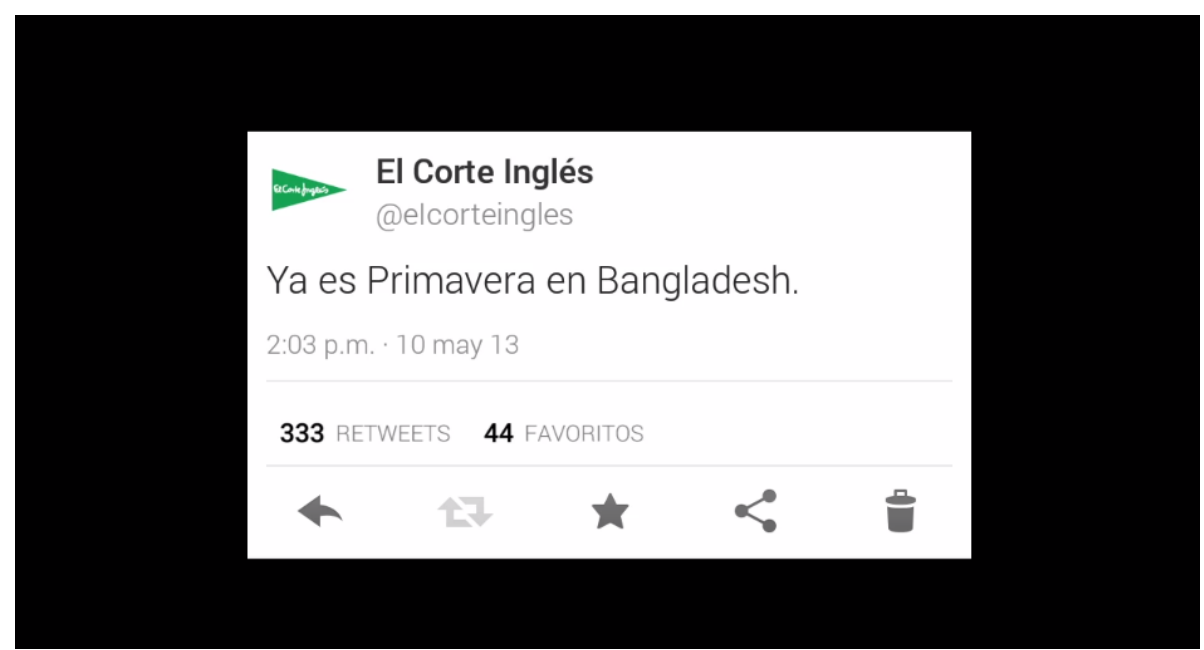

Imagen 3. Ikastrolla. Frame del video The Troll Face (2013). Acción de duplantación de El Corte Inglés. Recuperado de https://vimeo.com/88515951

\section{Verdad y Poder: Edipo como Metáfora del Poder del Pueblo}

A continuación, se analizan los casos de estudio desde dos visiones de la noción de verdad realizada por el filósofo M. Foucault. La primera visión procede del estudio que realiza sobre el teatro griego y en concreto sobre la representación de la figura de Edipo en la obra de Sófocles. El filósofo se desmarca de las interpretaciones que realiza Freud desde el campo del psicoanálisis donde la historia de Edipo representa la limitación del deseo. Foucault afirma que Edipo se usa como un instrumento de poder médico y psicoanalítico sobre el deseo y el inconsciente. Sin embargo, desde la perspectiva que plantea el filósofo el mito es un relato sobre el poder y el no poder. La tesis se basa en poner el foco sobre otro asunto de la historia, en el secreto. Todo el relato se basa en el hecho fundamental de que un personaje del pueblo posee el secreto, un pedazo que falta para completar la historia. Y ese conocimiento se convierte así en una herramienta de poder, pero de poder popular. Edipo tiene que ver no tanto con la profecía, con el futuro, sino con el pasado y con el testimonio como verdad. 
"Es un instrumento de poder, de ejercicio de poder que permite a alguien, que posee un secreto o un poder, fracturar en dos partes un objeto cualquiera, hecho de cerámica o de otro material, guardar una de las partes y confiar la otra a alguien que debe ser portador del mensaje o atestiguar su autenticidad. Gracias al acoplamiento de estas dos mitades se podrá reconocer la autenticidad del mensaje, es decir, la continuidad del poder que se ejerce. [...] La historia de Edipo es la fragmentación de esta pieza cuya posesión integral, reunificada, autentifica que se detenta el poder y las órdenes dadas por él. Los mensajes, los mensajeros, que el poder envía y que deben retornar, autentificarán su vínculo con el poder por el hecho de que cada uno de ellos detenta un fragmento de la pieza y puede acoplarlo a otros fragmentos. Tal es la técnica jurídica política y religiosa de lo que los griegos llamaron, $\sigma 0 ́ \mu \beta 0 \lambda o$ el símbolo.” (Foucault 1999, p. 192)

Foucault hace una lectura de las obras de Sófocles, Antígona, Edipo y Electra, como relatos sobre la democracia porque se trata de la dramatización de la historia del derecho griego y representa así:

\begin{abstract}
"un resumen de una de las grandes conquistas de la democracia ateniense: la historia del proceso mediante el cual el pueblo se apropió del derecho de juzgar, del derecho a decir la verdad, de oponer la verdad a sus propios amos, de juzgar a quienes los gobiernan." (Foucault 1999, p. 203)
\end{abstract}

La genealogía que desarrolla Foucault sobre la verdad en términos jurídicos a partir de la historia de Edipo tiene similitud con el activismo hacker ya que estas acciones consisten en extraer información secreta. Las personas y organizaciones que se dedican a este tipo de activismo político desempeñan un rol muy similar a los pastores en la obra griega. Conocen un secreto que, al revelarlo, es capaz de cambiar el curso de las cosas. Lo hacen, además, desde una posición donde no tienen poder y por eso han de recurrir a estrategias de desobediencia para conseguir o difundir esa información. Las tácticas activistas desobedientes se legitiman porque se sitúan en un lugar donde tienen "derecho a enfrentar una verdad sin poder a un poder sin verdad" (Foucault 1999, p. 203) 
En este sentido los fakes que se analizan aquí se denominan también hackeos, ya que se apropian de las identidades y del lenguaje dominante para subvertirlo. Los y las artistas del fake, en tanto que personajes sin poder y miembros del pueblo, tienen la capacidad de enfrentarse al poder. Pero en ambos casos se da la paradoja de que no revelan datos que permanecían en secreto. El rol de los y las autoras de los fakes se asemeja al rol de los pastores en el relato griego pero, aunque se reconoce esta similitud cabe asumir que hay una diferencia y es que no desvelan información oculta. Entonces, surge la siguiente pregunta: mediante el juego de espejos que realizan ¿qué tipo de verdad están desvelando?

\section{La Verdad como Discurso}

Para desentrañar esta cuestión interpretamos la noción de verdad también desde las aportaciones del filósofo, pero desde otro lugar. Foucault niega la existencia de una verdad objetivable ya que cada sociedad comparte una serie de discursos que producen una verdad y sirven para identificar lo verdadero de lo falso (Foucault 1981). A partir de esta interpretación es posible entender que las suplantaciones de las empresas Dow Chemical y El Corte Inglés producen otros discursos a los dominantes y que estos discursos tienen en sí mismos su propio estatuto de veracidad. Este estatuto de veracidad no depende entonces de estar sujeto a una ideología como ocurriría en un contexto de antagonismo ideológico como sucedía en el momento histórico donde Brecht escribe sobre el rol de los escritores.

"En sociedades como las nuestras la economía política de la verdad está caracterizada por cinco rasgos históricamente importantes: la verdad está centrada sobre la forma del discurso científico y sobre las instituciones que lo producen; está sometida a una constante incitación económica y política (necesidad de verdad tanto para la producción económica como para el poder político); es objeto, bajo diversas formas, de una inmensa difusión y consumo (circula en aparatos de educación o de información cuya extensión es relativamente amplia en el cuerpo social, a pesar de algunas limitaciones estrictas); es producida y transmitida bajo el control exclusivo pero dominante de algunos grandes aparatos políticos o económicos (universidad, 
ejército, escritura, media); finalmente es el envite de todo un debate político y de todo un enfrentamiento social (luchas "ideológicas")." (Foucault 1981, p. 144)

Foucault explica que verdad no es aquello que se descubre, sino que es aquello que se puede definir como "el conjunto de reglas según las cuales se distingue lo verdadero de lo falso y se aplica a lo verdadero efectos específicos del poder" (Foucault 1981, p. 144). La crítica a la idea de verdad está directamente dirigida a la focalización de la ciencia desde la definición del marxismo. La verdad está ligada circularmente a sistemas de poder que la producen y la sostienen, y a efectos de poder que inducen y la prorrogan. Podemos hablar de un "régimen" de la verdad. "Este régimen no es simplemente ideológico, superestructural; sino que fue una condición de formación y desarrollo del capitalismo. Y es el que, a reserva de algunas modificaciones, funciona en la mayor parte de los países socialistas (dejo abierta la cuestión de China, que no conozco)." (Foucault 1981, p.144)

La imagen pública tanto de Dow Chemical como de El Corte Inglés no se sostienen sobre una mentira, se sostienen sobre una verdad cargada de ideología y, por este motivo, se necesita de otras verdades para combatirlas. En estos casos analizados la verdad que se crea es, paradójicamente, mediante el engaño. El ejercicio de la retórica es la operación que posibilita que se dé esta paradoja.

\section{Ideología, Verdad e Intelectualidad}

Foucault pone en relación tres entidades clave: la ideología, la verdad y la figura del intelectual. Nos interesa esta relación ya que es posible establecer un paralelismo entre la figura del artista con la del intelectual.

"El problema político para el intelectual, no es criticar los contenidos ideológicos que estarían ligados a la ciencia, o hacer lo preciso para que la práctica científica esté acompañada por una ideología justa. Sino saber si es posible constituir una nueva política de la verdad. El problema no es cambiar la "conciencia" de la gente o lo que tienen en la cabeza, sino el régimen político, económico e institucional de producción de verdad. No se trata de liberar a la verdad de todo 
sistema de poder -sería una quimera, ya que la verdad es ella misma poder-, sino desligar el poder de la verdad de las formas de hegemonía (sociales, económicas, culturales) en el interior de las cuales funciona por el momento. La cuestión política, en suma, no es el error, la ilusión, la conciencia alienada o la ideología; es la verdad misma." (Foucault 1981, p. 145)

Después de realizar este análisis emergen dos cuestiones derivadas de la problematización de la verdad: una es el problema de la ideología y otra es la relación de con el público. Sobre la primera cuestión no se puede afirmar que las acciones de The Yes Men y de Ikastrolla estén cargadas de ideología pues desde el momento en que la cuestión de la verdad se aleja de la noción marxista, la idea de ideología marxista también se desdibuja. La verdad en este tipo de activismo político tiene un régimen distinto. Y la segunda cuestión tiene que ver con el público, la cual ha sido revelado gracias Foucault. El espectador o espectadora no puede concebirse como sujeto al cual se le desvela la verdad y, finalmente, se le conciencia. Las tácticas de apropiación se encargan de cuestionar esa verdad imperante, no demuestran lo que es verdad y lo que no, sino que se ocupan de reconstruir los discursos dominantes, de de-construir la verdad que impone el poder mismo. Las tácticas de los fakes mediáticos son capaces de desplazar la mirada hacia las estructuras que sostienen esa verdad para así desacreditarla. Las suplantaciones de las empresas Dow Chemical y El Corte Inglés dejan al descubierto el "conjunto de procedimientos regulados por la producción, la ley, la repartición, la puesta en circulación y el funcionamiento de los enunciados." (Foucault 1981, p. 145)

\section{Conclusiones}

La imagen pública de las empresas Dow Chemical y El Corte Inglés se sostiene sobre un concepto de verdad cargado de ideología. Las suplantaciones de estas empresas realizadas por The Yes Men e Ikastrolla, respectivamente, construyen mediante el engaño otras verdades con el objetivo de desvelar esta ideología. La verdad está ligada circularmente a sistemas de poder que la producen y la sostienen, y a efectos de poder que inducen y la prorrogan. Podemos hablar entonces de que existe un régimen 
de la verdad. Por otro lado, no se puede afirmar que las acciones de The Yes Men y de Ikastrolla estén cargadas de ideología ya que las estrategias de este tipo de acciones no tratan de confrontar una verdad frente a una falsedad. No se inscriben bajo un paradigma donde lo real se sitúa como lo contrario de aquello representado.

En este tipo de acciones la cuestión de la verdad se aleja de la noción marxista donde aquello objetivable se puede mostrar mediante un método científico. Las falsificaciones mediáticas se encargan de dejar al descubierto el conjunto de procedimientos regulados y el funcionamiento de los enunciados y estructuras que organizan los discursos que se presentan como verdaderos. Los fakes no demuestran lo que es verdad y lo que no, sino que se ocupan de reconstruir los mecanismos que organizan los discursos dominantes. En los casos concretos analizados la retórica y la apropiación de los códigos visuales hace que se vuelvan transparentes los entresijos de la maquinaria del marketing de las empresas responsables de los accidentes y las víctimas.

Además de identificar el problema de la verdad planteado en un inicio ha emergido una cuestión no prevista en los objetivos originales. Estos tienen que ver con el rol de los y las activistas, los cuales, en un ejercicio de desobediencia devuelven el poder a los sin poder. Lo hacen, no de una manera didáctica a través de la que se intenta concienciar a los públicos, sino que se realiza construyendo un régimen distinto de verdad. La forma en que operan apunta una nueva línea que sería interesante investigar y que tiene que ver con otras concepciones de la didáctica y la pedagogía en las acciones activistas de la tipología aquí estudiada.

\section{Referencias}

Bal, M. (2002). Conceptos viajeros en las Humanidades. Una guía de viaje. Murcia: Cendeac Ad Litteram.

Bilchbaum, A., Bonano, M., \& Engfehr, K. (Directores). (2010). The Yes Men Fix the World. [DVD video]. Estados Unidos: Rezo Films y HBO Documentaries.

Brecht, B. (1984). El compromiso en literatura y arte. Barcelona: Ediciones Península. 
Català, J.M. (2013). "Políticas de la realidad”. En: Revista da Facultad de Biblioteconomía e Comunicaçao da UFRGS 19(1), pp. 313-333.

Dery, M. (1993). "Culture Jamming: Hacking, Slashing, and Sniping in the Empire of Signs". (En línea). Open Magazine Pamphlet Series, 25. [Consulta: 15/06/2011]. Disponible en:

http://markdery.com/?page_id=154

Foucault, M. (1981). Un diálogo sobre el poder, y otras conversaciones.

Madrid: Alianza.

Foucault, M. (1999). "La verdad y las formas jurídicas". En: Estrategias de poder. Obras esenciales. Volumen II. Barcelona: Paidós Básica.

Gadamer, H.G. (2007-2010). Verdad y método. Salamanca: Sígueme. Ikastrolla. (2013). The Troll Face. [Video en línea]. Disponible (privado) en: https://vimeo.com/88515951

Lazzarato, M. (2006). La máquina. [en línea]. Viena: EIPCP Instituto Europeo para las Políticas Culturales Progresivas. [Fecha de consulta: 10/02/2015]. Disponible en:

http://eipcp.net/transversal/1106/lazzarato/es

Rodríguez, E., Sánchez Cedillo, R. (eds.) (2004). Capitalismo cognitivo. Madrid: Mapas. Traficantes de sueños.

Sandoval Casilimas, C. A. (1996). Investigación cualitativa. Bogotá:

Universidad de Antioquia Módulo 4. Instituto colombiano para el fomento de la educación superior. ICFES Módulos de Investigación Social.

Sardar, Z., Val Loon, B. and Apignanesi, R. (2005). Estudios culturales para todos. Barcelona: Paidós Ibérica.

\section{Elena Gabriela Fraj Herranz: Profesora asociada.}

\section{Email address: elefrajgb@ub.edu}

Contact Address: Departamento de Artes Visuales y Disseño. Facultad de Bellas Artes. Universitat de Barcelona. Edificio Florensa, Despacho de Imagen 2. Carrer Adolf Florensa 8, 08028 Barcelona. España. 